\title{
QUEM HÁ DE ACREDITAR? - UM POEMA DESCONHECIDO DE FLORBELA ESPANCA NO BRASIL?
}

\author{
WHO WILL BELIEVE IT? - AN UNKNOWN \\ POEM BY FLORBELA ESPANCA IN BRAZIL?
}

\author{
Andreia Alves Monteiro de Castro ${ }^{1}$ \\ Eduardo da Cruz $z^{2}$
}

\section{RESUMO}

A partir da pesquisa sobre a presença de escritoras portuguesas na imprensa periódica brasileira, principalmente naquela dedicada à colônia portuguesa imigrante no Brasil, localizou-se um poema assinado por "Soror Saudade" na revista Portugal, dirigida literariamente por Rui Chianca. Discute-se a possibilidade de a autoria ser de Florbela Espanca. Primeira recepção de Florbela Espanca no Brasil. Possíveis ligações entre o diretor da revista e a escritora portuguesa. Aproximações entre o poema e a escrita de Florbela Espanca. Edição do poema.

PALAVRAS-CHAVE: Florbela Espanca, Rui Chianca, poesia portuguesa, relações luso-brasileiras, imprensa periódica

\section{ABSTRACT}

From the research on the presence of Portuguese women writers in the Brazilian periodical press, especially the one dedicated to the Portuguese immigrant colony in Brazil, a poem signed by "Soror Saudade" was found in the magazine Portugal, directed by Rui Chianca. The possibility of Florbela Espanca's authorship is discussed. First reception of Florbela Espanca in Brazil. Possible links between the magazine's director and the Portuguese writer. Approximations between the poem and the writing of Florbela Espanca. Poem edition.

KEYWORDS: Florbela Espanca, Rui Chianca, Portuguese Poetry, Luso-Brazilian Relations, Periodical Press 
Quando um projeto de pesquisa começa, o pesquisador tem objetivos em vista e espera alguns resultados. Algumas vezes, há desvios de rotas. Se o corpus é constituído por fontes primárias, como manuscritos ou publicações na imprensa periódica, o caminho é mais incerto. Como esses textos não foram previamente acessados, muito menos lidos, pelo pesquisador, só serão descobertos ao longo da pesquisa, numa primeira fase. Logo, podem surgir fontes com informações não previstas. É o caso da publicação que apresentamos aqui.

Há um encadeamento de descobertas que foi levando a novas pesquisas. A partir do projeto O Real em Revista, desenvolvido por pesquisadores do Polo de Pesquisas Luso-Brasileiras, grupo sediado no Real Gabinete Português de Leitura, com patrocínio Petrobras-Cultural, entre 2013 e 2015, que procurava preservar e divulgar o acervo de periódicos daquela biblioteca, tomamos conhecimento de uma série de jornais e revistas criados pela colônia portuguesa no Rio de Janeiro e a quase inexistente colaboração feminina em suas páginas. Dessas pesquisas anteriores, surgiu o projeto atual $^{3}$, que busca identificar as escritoras portuguesas que estiveram no Brasil entre 1890 e 1930 e o que publicaram na imprensa brasileira, sobretudo naquela voltada para a colônia lusa. O objetivo é perceber as imagens de Portugal que foram veiculadas junto aos seus patrícios imigrantes e o que escreveram sobre o Brasil a partir dessa viagem. Também estamos atentos às redes de sociabilidades que articularam para estabelecer essas ligações entre os campos literários português e brasileiro. Assim, além de resgatarmos do esquecimento algumas escritoras portuguesas da primeira metade do século XX - incluindo-as ao lado das mais conhecidas hoje, ou menos desconhecidas, melhor dizendo, Florbela Espanca (1894-1930), Judith Teixeira (1880-1959) e Irene Lisboa (1892-1958) -, podemos reconhecer o papel que desempenharam nas relações culturais luso-brasileiras e na construção do imaginário português no Brasil.

Então, a primeira fase do projeto previa a busca pela presença feminina nos periódicos da colônia portuguesa no Brasil nas primeiras décadas do século XX. São muitos os periódicos editados nesse período ${ }^{4}$. Infelizmente, os pesquisadores têm dado mais atenção à imprensa de outras colônias imigrantes, nomeadamente as de língua estrangeira, de modo que as pesquisas que pretendem tomar por base a imprensa portuguesa no Brasil precisam, em primeiro lugar, recuperar esses títulos, locais e datas de publicação. Restringimo-nos, inicialmente, aos catálogos do Real Gabinete e da Fundação Biblioteca Nacional, o que explica, em parte, a predominância de publicações do Rio de Janeiro.

Esperávamos encontrar um número restrito de escritoras portuguesas nesses periódicos, pois o projeto partia do conhecimento de algumas que teriam visitado o Brasil nas primeiras décadas do século XX. É o caso, por exemplo, das autoras Ana de Castro Osório (1872-1935), Olga de Morais Sarmento (1881-1948), Branca de Gonta Colaço (1880-1945), Virgínia Quaresma (1882-1973), Mariana Coelho (1857-1954), Maria da Cunha (1862- 
1917), Emília de Sousa Costa (1877-1959) e Maria O’Neill (1873-1932). A pesquisa nos periódicos do acervo do Real Gabinete Português de Leitura levou-nos a outras escritoras que estiveram no Brasil, algumas conhecidas, como Sara Beirão (1884-1974), outras sobre quem pouco ou nada sabemos, como Maria do Céu Vasconcellos Mello. Há, também, intensa colaboração copiada ou enviada de Portugal, de autoras, sobretudo poetisas.

Esse levantamento inicial confirma que as duas poetisas do início do século XX mais reconhecidas hoje, Florbela Espanca e Judith Teixeira, não eram valorizadas, ou talvez não fossem mesmo conhecidas junto à comunidade portuguesa no Brasil. Florbela só ganha visibilidade junto aos imigrantes portugueses após sua morte. Judith Maggiolly, em sua "Crónica da Quinzena”, presente na Lusitânia: revista ilustrada de atualidade e de aproximação luso-brasileira, n. ${ }^{\circ}$ 54, de 16 de abril de 1931, confirma o desconhecimento que havia sobre as poesias florbelianas nos dois lados do Atlântico:

Florbela Espanca, espírito subtil, alado de quiméricas fantasias, pairando no infinito, buscando ansioso um ideal melhor, que foi talvez a maior poetisa do nosso tempo, nasceu, viveu e morreu ignorada na terra portuguesa.

Serviu de berço ao seu primeiro sorriso, á sua inspiração, ao seu primeiro verso, as campinas, os prados floridos de vermelhas papoilas, o murmurar dos regatos, toda a paisagem risonha fresca e colorida do formoso Alentejo.

Criou e acalentou o seu primeiro amor o brilho doirado do nosso belo sol com o grito vibrante dos seus raios de fogo que lhe penetraram na alma e lhe insuflaram a ansia, a sêde ardente de viver! Ou de morrer!

E cobriram a sua derradeira camélias recortadas, rosas de Portugal, toda a variegada flora desta terra tão rica de perfumadas flores que embalsamam o ar por onde vagueia a alma genial e clarinha de Florbela, a sua rainha, a mais bela de todas!

$[\ldots]$

A desditosa vida de Florbela, que cêdo procurou na morte os alivios aos males de amor, passou por nós roçagando. Tão diáfano era todo o seu sêr, que não démos por ela, não a adivinhamos! O seu livro "Charneca em flor", que só agora tão tardiamente foi consagrado justamente, é todo uma canção ao seu amor dolorido, todo êle impregnado da beleza extraordiária da sua alma!

Embrenharmo-nos nêle é saborear com ela todos os seus ansios, todos os seus queixumes, o desespêro enlouquecido da desilusão, a pulsação alterada dum coração amoroso. (MAGGIOLLY, 1931, p. 26-27).

A crônica traz ainda os sonetos "À janela de Garcia de Resende" e "O teu olhar", além da informação de que seria erguido um busto da poetisa no jardim principal de Évora. 
Na mesma revista, no número 78, de 16 de abril de 1932, Maria de Carvalho dedica-se à Florbela na coluna "Figuras Imortais", confirmando ser ela uma desconhecida:

Não conheci Florbela Espanca, nunca a vi, creio eu; sei dela, apenas o que tenho lido em revistas e jornais [...]

Há alguns anos, trouxeram-me, um dia, um livro duma nova poetisa: "Soror Saudade" era o título do livro, era como Florbela chamava a si própria. Li-o e não me fez grande impressão, tanto que esqueci o livro e a autora.

Ultimamente, apesar das preocupações e cuidados que têm complicado a minha vida, interessaram-me os sonetos que li nos jornais e mandei vir a "Charneca em flôr". Nêste livro senti palpitar um coração ardente, dolorido e profundo, através dum talento impetuoso, férvido, pungente, rico de expressão verbal, cheio de clarões e de espinhos, recamado de flôres silvestres e gritos, e que é, realmente, com as suas urzes de orquideas estranhas (CARVALHO, 1932, p. 34).

Chamamos atenção para o fato de Florbela Espanca ser então conhecida por Soror Saudade, apesar de seu nome estampar a capa da primeira edição do Livro de "Sóror Saudade", de 1923, em consonância com a recomendação da diretora do suplemento feminino d'O Século, Modas e Bordados, de que não tomasse um pseudônimo 5 .

Maria de Carvalho ainda comenta dois retratos de Florbela, o que acompanhava a publicação de Charneca em Flor e um que ela vira no Portugal Feminino. Maria ignorou, portanto, o famoso retrato das "Senhoras Intelectuais Portuguesas" que tomaram parte no chá de despedida da diretora dessa revista, Maria Amélia Teixeira, que estava partindo para o Brasil (Fig. 1). Ficamos assim sabendo que nessa reunião estavam as duas presentes.

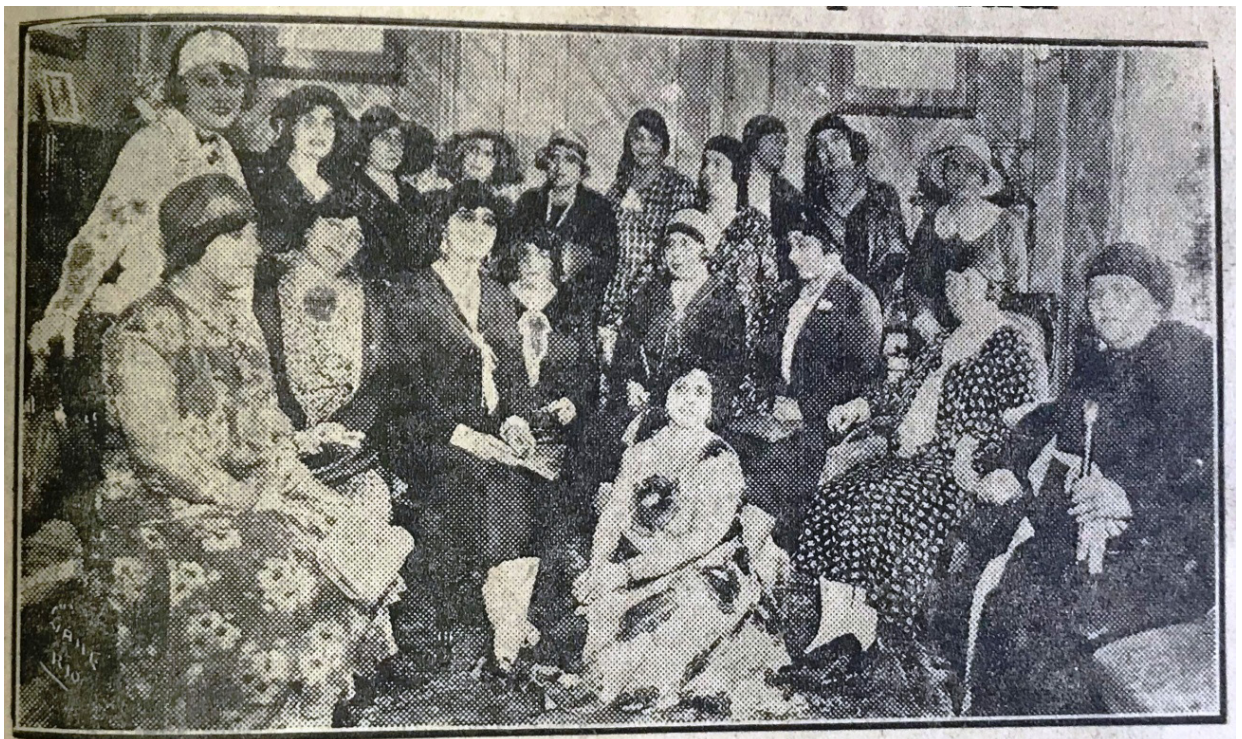

Fig. 1 - "Grupo de senhoras intellectuaes que tomaram parte no chá de despedida á senhora D. Maria Amelia Teixeira” (Pátria Portuguesa n. 299, de 30 de agosto de 1930, p. 1). Florbela é a quarta em pé, da esquerda para a direita. Maria de Carvalho é a quinta, sentada, da direita para a esquerda. 
Essa fotografia também foi reproduzida no Pátria Portuguesa n. ${ }^{\circ} 299$, de 30 de agosto de 1930, na qual se encontram, ao redor de Maria Amélia, além das duas escritoras, Maria Rio de Carvalho e Florbela Espanca, Ana de Castro Osório, Emília de Sousa Costa, Helena de Aragão, Maria Nóbrega, Sara Beirão, Branca de Gonta Colaço, Elvira Guimarães, Helena Bianchini, Adelaide Felix, Laura Chaves, Maria de Cabedo, Fernanda de Castro, Teresa Leitão de Barros, Rosa Silvestre, S. Portugal e Alice Ogando. Essa publicação brasileira, ao nomear as autoras, troca o nome de Florbela, que aparece grafado como "Florbella Esperança" - mais um indício de seu desconhecimento junto ao público português no Brasil.

Antes de seu falecimento, uma busca por seu nome na Hemeroteca Nacional revela muito pouco. Florbela Espanca Lage ${ }^{6}$ aparece apenas como tradutora dos romances Dois Noivados, de Champol, vendido pela Empreza de Publicações Modernas, na avenida Henrique Valladares, 145, no Rio de Janeiro, que anunciava no Pelo Mundo ${ }^{7}$; do Dona Quichotta, de Georges de Peyrebrune, vendido em Pelotas (RS), pela Livraria Universal'; de A Ilha Azul, de Georges Thierry, publicado em folhetim no Diário de Pernambuco a partir do número 34 de 10 de fevereiro de 1927, e também anunciado pela Livraria Universal na Illustração Pelotense no mesmo ano'; e ainda de O Romance da Felicidade, de Jean Rameau, que "pertence à excellente Bibliotheca do Lar, da Livraria Civilisação, do Porto, e foi primorosamente vertido para portuguez pela escriptora Florbella Espanca Lage", como indica a coluna "Livros Novos" do jornal carioca A Noite10.

Devido a esse desconhecimento do público brasileiro, uma publicação prévia de Florbela Espanca no Brasil pode ter passado despercebida, principalmente se estivesse assinada simplesmente por Soror Saudade, sobretudo num periódico da colônia portuguesa que não se encontra digitalizado, mas guardado no Real Gabinete Português de Leitura. Referimo-nos ao poema "A Moda", publicado na revista Portugal n. ${ }^{\circ}$ 2, de 1923, que reproduzimos com ortografia atualizada sem alterar a pontuação ou a sonoridade:

\title{
A MODA
}

Por SOROR SAUDADE

\author{
- Convento da perfeição \\ Montanha d'Alto Sonhar - \\ Às que pelo Mundo vão \\ Ansiosas dencantar.
}

Chamam-me "Soror Saudade",

- Que o passado é meu enlevo...

Mas... sobre modas... quem há-de

Acreditar no que escrevo?! 
Não é a Moda, o Presente

Palpitante, que varia?!

A cada instante dif'rente?

Sempre nova em cada dia?!

Pois essa mesma razão

Que deste assunto me aparta,

Foi buscar-me pela mão

Para escrever esta carta!...

À força de variar,

A Moda, linda, a sorrir,

Acaba por evocar

O Passado ao que há de vir!...

Tutankhamen ${ }^{11}$, enterrado

Há três mil anos ou mais,

Dormindo, mumificado,

Numa cova, entre areais;

Faraó onipotente,

Deus da Moda em seu país,

Mal ressurge e, de repente,

Ordena a Moda em Paris!...

As linhas altas, graciosas,

De frescos murais ignotos,

Passam em curvas formosas

Que recordam flor's de lótus!

Longos vestidos plissados

Que se alargam adiante

Aos passos cadenciados

Dum movimento ondulante;

Rendas, véus, sedas bordadas

De figurinhas patrícias;

Fantasias inspiradas

Nas áureas modas egípcias;

Sob o klaft dos toucados

Penteados bem cingidos;

E os rostos emoldurados

Pelos pingentes brunidos;

Tez morena, olhos de fogo

Dos mais estranhos matizes;

Eis a Moda erguendo o rogo

À múmia da deusa Îsis!... 
Num coval ou num museu

O velho Egito dormita

Tal e qual como morreu!

A Moda não!... Ressuscita!

Transformada, redimida;

Mais sutil e espiritual!

Perpétua dona da Vida!

Como divina, imortal!

Bendita a Moda! Saudade

Que a Morte envolve d'enganos!

Pois a velha Humanidade

Remoçou de três mil anos!...

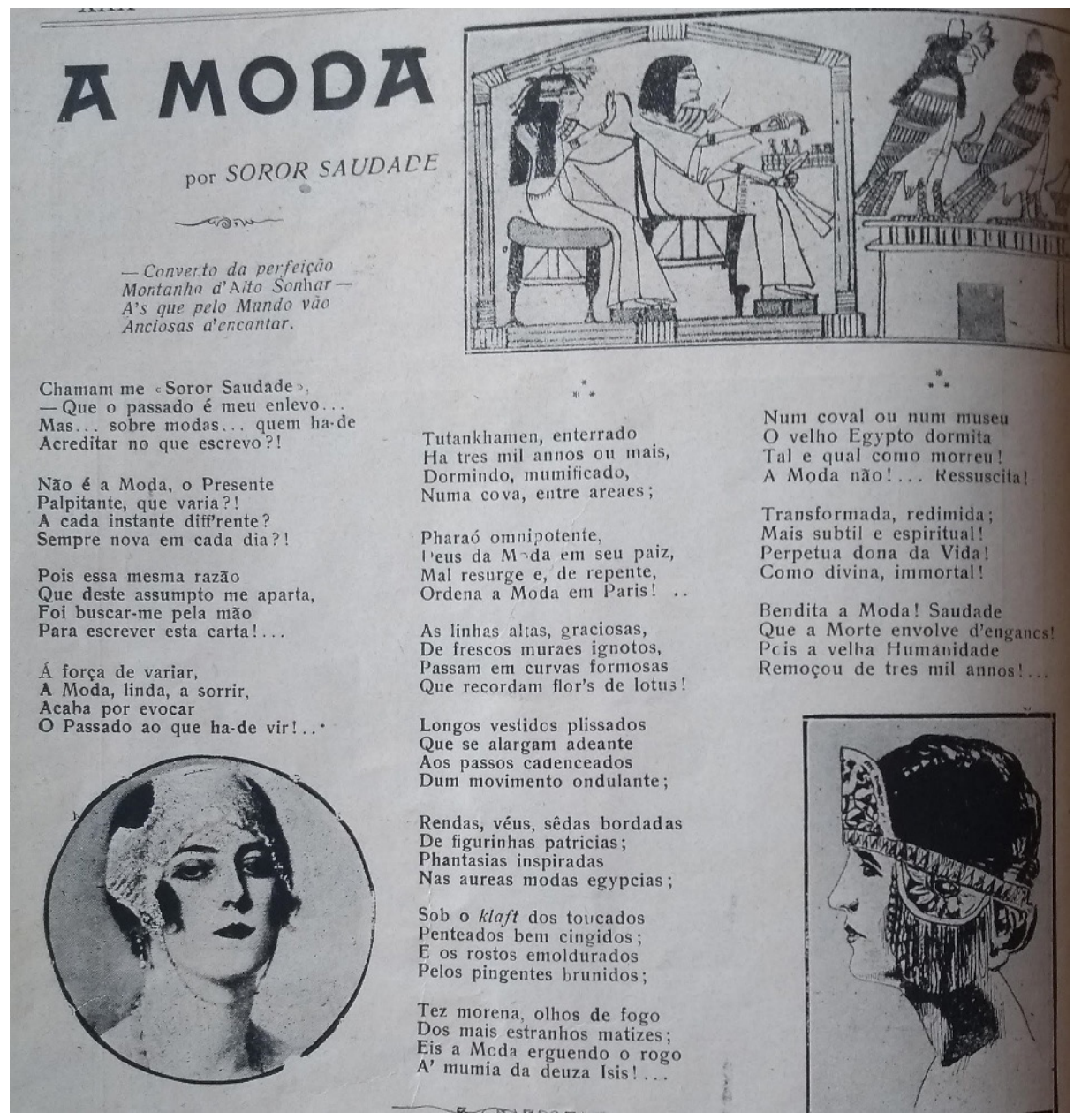

Fig. 2 - Reprodução do original publicado na revista Portugal n. ${ }^{\circ}$ 2, de 31 de agosto de 1923, p. XXX.

Trata-se de um poema que não consta nem dos livros preparados por Florbela Espanca publicados em vida ou póstumos nem nos manuscritos conhecidos, ou em periódicos portugueses. No entanto, quando lemos as quadras, imediatamente pensamos ser efetivamente da poetisa de Évora, mas não consta na edição de poemas preparada por Maria Lúcia Dal Farra ${ }^{12}$ 
nem na organizada por Michelle Vasconcelos Oliveira do Nascimento ${ }^{13}$. Seria, então, possível confirmar a autoria? Como esse poema teria chegado até o Rio de Janeiro para ser publicado? Qual a relação entre esse texto e os demais escritos de Florbela Espanca?

O poema foi publicado no número 2 da Portugal: revista Portuguesa, em 31 de agosto de 1923. Esse periódico tinha Rui Chianca como diretor literário e o comendador Oliveira Guimarães como diretor gerente. Os dois eram figuras de destaque na colônia portuguesa no Rio de Janeiro. Rui Chianca, inclusive, fazia sucesso com suas peças nos teatros da capital. É dele o projeto da revista, divulgado em maio de 1923. O País, inclusive, traz diversas notinhas alusivas às homenagens ao Chianca realizadas naquele mês em prol da revista que ele pretendia publicar ${ }^{14}$. Nesse evento, ele teria apresentado o programa da publicação, que vem no primeiro número, com o título "Para quê?", no qual afirma que:

A revista Portugal era, de há muito, uma aspiração ardente e uma necessidade real das Colonias Portuguezas no Brasil. A aspiração realizou-se. O tempo dirá se as imperfeições da obra respeitaram os intuitos da idéa.

Mostrar ao Brasil o que há de bom em Portugal e inversamente, sem exaggeros sentimentaes, mas apresentando nos seus justos planos tudo o que merece applauso, e não é pouco. (Portugal n. 1, 14 de agosto de 1923, p. II).

No mesmo texto de justificativa, ratifica o título da revista: "Portugal se chama e não Brasil-Portugal nem Luso-Brasileira”. Valoriza assim os assuntos e os escritores portugueses. Também exclui tanto a política brasileira quanto a portuguesa dos temas que pretende abordar em seu periódico, destacando-se, portanto, da rivalidade entre monárquicos e republicanos portugueses presentes no Brasil naquela época.

Em junho daquele ano, o jornal $A$ Noite indicava que a revista estava quase pronta para ser lançada, o que deveria ocorrer na segunda quinzena do mês seguinte. Contudo, a data escolhida foi a de 14 de agosto, comemorando a batalha de Aljubarrota e assim aproveitando a publicidade ao redor de Rui Chianca, que fizera sucesso com sua peça Aljubarrota nos teatros cariocas.

Talvez esteja nos dois diretores da Portugal, mais provavelmente no Rui Chianca, diretor literário, o possível vínculo com Florbela Espanca. Como temos destacado, a poetisa era então uma desconhecida no Brasil, mesmo junto aos imigrantes portugueses. Segundo as cartas ao seu irmão Apeles publicadas por Maria Lúcia Dal Farra ${ }^{15}$, é o aviador o foco de interesse da calipolense sobre o Brasil.

E é em Apeles que reside a única alegria de Florbela nesse tempo de amarguras diante dos destinos da sua Pátria. Ele tornara-se piloto (e depois Primeiro-Tenente) da Força Aérea da Marinha Portuguesa, e participa, durante o ano de 1922, de 
uma relevante façanha nacional: a da Travessia do Atlântico Sul, empreendida por Gago Coutinho e Sacadura Cabral. Apeles parece encarnar o que Florbela almejara sempre para a nova geração republicana - e afirmo isso com os olhos fitos no seu projeto literário Alma de Portugal, produzido em 1916, quando, então, representando a ala mais progressiva da nascente República Portuguesa, a Poetisa criara os poemas para o livro que seria uma homenagem humilíssima à pátria que estremeço. (DAL FARRA, 2012, pp. 24-25).

Maria Lúcia Dal Farra confirma a estada de Apeles Espanca no Brasil, em Fernando de Noronha, Vitória e Rio de Janeiro, pelas cartas de Florbela a ele destinadas. Os jornais brasileiros também testemunham a façanha dos aviadores portugueses e todas as festas, recepções e homenagens a Gago Coutinho, Sacadura Cabral e aos tripulantes do Carvalho Araujo, navio onde servira Apeles Espanca no transporte do avião Fairy Santa Cruz, o segundo utilizado na travessia. Podemos reparar, por essas notícias, o papel de destaque desempenhado pelos dois diretores da revista Portugal nessas homenagens.

O Correio da Manhã, de 2 de junho de 1922, no artigo "O raid aereo Lisboa-Rio: a recepção aos valorosos aviadores portuguezes", transcreve um ofício dos membros da Sociedade de Geografia de Lisboa no Rio de Janeiro ao presidente da Comissão Executiva da Colônia Portuguesa para a Recepção dos Aviadores Comandantes Sacadura Cabral e Gago Coutinho informando que pretendiam representar aquela associação nos atos públicos de recepção e que, em nome dela, entregariam aos dois aviadores "uma saudação em verso do illustre escriptor sr. Ruy Chianca, manuscripto em pergaminho illuminado pelo primoroso pintor Corrêa Dias" (Correio da Manhã n. 8489, 02/06/1922, p. 3). Assinam o ofício: Visconde de Moraes, Comendador Oliveira Guimarães, Diniz e Francisco Rodrigues da Cruz.

O País, de 23 de junho de 1922, apresenta na primeira página as notícias sobre diversas festividades de homenagem aos aviadores. Dentre elas, destacamos a realizada "No Theatro Lyrico" no dia anterior, com os dois aviadores e os capitães do República e do Carvalho Araújo no palco, onde "o actor Raphael Marques leu uns patrioticos versos de Ruy Chianca, em homenagem aos dois heroes, versos que foram muito applaudidos" ( $O$ Paiz a. XXXVIII n. 13.760, 23/06/1922, p. 1), seguido de vários discursos, como o de António Ferro.

A Rua, de 26 de junho, no artigo "'Raid' Lisboa-Rio" informa que os aviadores estiveram no dia anterior no Derby Club. "Além dos aviadores, compareceram a essa reunião as officialidades dos cruzadores 'Carvalho Araujo' e 'Republica"' (A Rua n. 144, 26/06/1922, p. 1) em evento cuja "comissão de recepção" era composta também por Francisco A. de Oliveira Guimarães.

No mês seguinte, nova festividade, na sede do Flamengo Football Club, para a entrega do valor arrecadado por uma subscrição popular para a compra de um hidroavião nomeado Portugal-Brasil. A comissão responsável 
pela ideia e pela arrecadação era composta por, entre outros, o Comendador Oliveira Guimarães, que fora convidar o presidente no Palácio do Catete para que participasse da entrega ${ }^{16}$. O mesmo comendador, com os demais membros da comissão, senador Sampaio Correia, Raphael Pinheiro, Raul Pederneiras, Carlos Costa e N. Bittencourt, receberam os pilotos do Fairey 17. Então, "o Sr. Erico Braga, da companhia Lucillia Simões, leu, com grande calor, os formosos e patrioticos versos de Ruy Chianca, de homenagem aos dois pilotos irmãos, sendo muito applaudido". Ao final, "rodeados pela enorme assistencia que queria abraçal-os, e debaixo de freneticas acclamações e verdadeira chuva de flores, retiraram-se então os dois arrojados aviadores, em companhia dos commandantes do 'Republica' e 'Carvalho Araujo'” ( $O$ Paiz n. 13797, 30/07/1922, p. 4).

O “Carvalho Araujo" partiu do Rio em agosto, chegou a Maceió no dia 7 daquele mês ${ }^{17}$, mas foi instruído a se dirigir a Cabo Verde para conduzir o chefe do estado português ao Rio de Janeiro ${ }^{18}$. Logo, em setembro, para as comemorações do centenário da independência do Brasil, o cruzador estava novamente na baía de Guanabara ${ }^{19}$. O tenente Espanca aparece, juntamente com outros oficiais, embaixadores e demais personalidades, na coluna "Bailes", d'O País de 14 de setembro de 1922, como estando presente na festa realizada no dia anterior pela marinha inglesa no Atlântico Sul "abordo do formidavel vaso de guerra Hood, em honra das missões especiaes, corpo diplomatico, altas autoridades e nossa sociedade" (O Paiz n. 13843, 14/09/1922, p. 5).

A oficialidade do Carvalho Araujo participou, então, de uma série de atividades e recepções, ao menos entre junho e setembro de 1922. Em muitas delas, tiveram participação especialíssima o escritor Rui Chianca e o comendador Guimarães. Teriam feito contato ou, quem sabe, amizade com o tenente Espanca? Afinal, estavam todos envolvidos no mesmo ideal de glorificação nacional. Também é importante destacar que, pelas cartas conhecidas, esse é o período de finalização do Livro de "Sóror Saudade". A carta de Florbela para Apeles, de 15 de julho daquele ano, mostra que ela estava com saudades, querendo notícias que os jornais portugueses não davam. Quando voltaria o irmão? Mais do que isso, ela cobra dele a capa para seu livro: "A capa do meu livro será do Brasil que virá?..." (ESPANCA, 2012, p. 234). Na carta de 5 de setembro, a irmã do tenente continua sem saber quando ele regressará. Sabemos pelas notícias dos jornais brasileiros que seu navio participara das comemorações do 7 de setembro. E a capa do livro? É nesse período de viagem que Florbela parece aproximar seu trabalho literário do perfil artístico do irmão:

Florbela parece se alegrar ao tocar no trabalho de Apeles publicado pela Ilustação; ela o fará prometer que preparará a capa do Livro de Sóror Saudade; e, de fato, a aquarela que Apeles criou para tal (pertença, hoje, do Grupo Amigos de Vila Viçosa), num estilo art déco, dá justamente a impressão de ilustrar a descrição que Florbela faz de si mesma: sentada 
numa cadeira da Ilha, com um livro sobre o regaço, viajando pelo mundo afora, devaneando - a própria mulher que vive pela imaginação, como ela mesma se pinta. (DAL FARRA, 2002, p. 170).

Nessas recepções, caso tenham conversado, Apeles e Rui Chianca, sobre o que falariam? De certo o tenente contaria ao poeta ufanista da pátria que ele tinha uma irmã poetisa, que estava finalizando um livro e que se assinava Soror Saudade. Assim, alguns meses depois, no final do primeiro semestre de 1923, quando resolve realizar o projeto da revista, Chianca poderia ter se lembrado do caso e escrito a Apeles pedindo algo da Soror Saudade, para encher sua revista cujo teor tradicionalista e histórico é claro e a denominação assumida por Florbela se encaixaria nesse modelo - que é, claro, invertido pela poetisa, algo que Rui Chianca não deveria imaginar.

Assim, já no segundo número, a revista apresenta o que deveria ser a "seção feminina", incluindo um "serão das poetisas", com colaborações fixas. Quando da abertura da seção, a redação indicava que o conteúdo seria:

Paginas leves - menos leves, porém do que o fumo que se esvae sem si deixar memoria de perfume, que é o espirito da phrase, a lição do conselho, a delicadeza do commentario paginas leves, como rendas finissimas têm de ser estas que para as almas femininas se destinam.

Apenas esboçado neste momento o programma, que nos seguintes será desenvolvido, ás donas de Portugal e do Brasil o dedicamos com venia palaciéga do seculo XVIII.

Tres collaborações effectivas honrarão estas columnas:

A de "Soror Saudade", a de "Madame de Beaulieu" e a do pintor já illustre que é Jorge Barradas.

"Madame de Beaulieu" falará da arte de ser bella, da sciencia complicada e transcendente do viver feminino;

Jorge Barradas, dos encantos do lar;

"Soror Saudade", da perfeição do amor. (Portugal n. 2, 31 de agosto de 1923, p. XXXIII).

Os planos acabaram não se cumprindo exatamente assim, pois a colaboração da "Soror Saudade" ficou apenas no poema "A Moda". Se a autoria for realmente de Florbela Espanca, é possível entender a limitação à primeira aparição, afinal esta seção se propõe a incentivar a manutenção das mulheres nos papéis sociais que lhe eram atribuídos. Também é possível reparar que a revista incentivava o uso de pseudônimos nas colaborações femininas. "Madame de Beaulieu" continua nos sendo uma desconhecida. Ocupará, mais tarde, esse lugar na revista uma portuguesa residente no Brasil que se assina Violante de Dénis, provavelmente também um pseudônimo, e Maria de Carvalho assinará diversos textos como "Miriam". 
Não fosse essa a rede que ligaria Rui Chianca a Florbela Espanca, poderia ele ter conhecido a poetisa de outra forma? A Portugal valorizava a geração nova de poetas portugueses. Publicou, inclusive, poemas e elogios a poetas próximos à antiga aluna de Direito, como Américo Durão e João Botto de Carvalho, "prosseguindo na agradavel tarefa de tornar conhecidos no Brazil os novos escriptores portuguezes" (Portugal n. 11, 15/01/1924, p. XXI).

Quanto ao estilo, mesmo não sendo um soneto - e Florbela não escreveu apenas sonetos! - há muitos pontos de contato entre esse poema e suas outras produções. Ademais, como afirma Dal Farra (1994), a presença de dezenas de quadras em redondilha maior no primeiro manuscrito de Florbela, o intitulado Trocando Olhares, evidencia a predileção da poetisa, quando iniciante, por essa medida típica da tradição portuguesa, ainda que tais poemas nunca tenham sido publicados por Florbela:

A evidência que salta à vista, como já frisei dentro desta primeira obra de Florbela, é a da predominância da redondilha maior na sua configuração popular, o que desencadeia questões concernentes à importância, ao sentido e ao papel que tal medida cumpre aqui (DAL FARRA, 1994, p. 28).

Estritamente relacionadas à oralidade e, portanto, provavelmente apreendidas por oitiva, o diálogo estabelecido por Florbela com as quadras populares, com reminiscências das cantigas medievais, pode ser considerado como o ponto de partida de um percurso poético fortemente marcado pelo experimentalismo e pelas interlocuções com outros textos e autores ${ }^{20}$, cujo destino seria a culta composição dos sonetos:

Como se trata da sua mais antiga tentativa de projecto poético, o exame dessa tendência inicial se torna determinante, sobretudo quando, sabemos, Florbela jamais apresentará quadras em nenhum de seus livros publicados, abandonando, em definitivo, tal forma poética e adoptando para sempre o soneto, unicamente através do qual se fará conhecer (DAL FARRA, 1994, p. 28).

Ainda segundo Dal Farra, as licenças poéticas, próprias da trova popular, também são em Florbela uma forte presença. Nesses textos da juventude, esse recurso pode ter sido empregado pela poetisa por dificuldade de contenção do número de sílabas dentro do verso ou, sobretudo, para registrar a dicção oral portuguesa. Essas licenças poéticas ocorrem também em alguns versos do poema "A Moda", encontrado na revista Portugal. O verso “Que recordam flor’s de lótus!”, o último da sétima quadra, teve o seu número de sílabas reduzido, a partir da síncope sofrida pela palavra flores, para se tornar um heptassílabo. Já em “A cada instante dif'rente?”, a eliminação da vogal parece mesmo concretizar a pronúncia do Português europeu.

Obviamente, essa trajetória poética de Florbela não só consiste em mudanças na métrica como também no esquema rimático. Há uma passagem das quadras com rimas apenas entre versos pares a sonetos de rimas cruzadas e/ou interpoladas no Trocando Olhares: 
Assim, além da divergência de princípios, o que separa um montante do outro, divide o manuscrito em um terço, de um lado, e em dois terços, do outro, é a forma literária neles praticada. Deste modo, enquanto o grupo inicial de 30 peças sustenta o império da métrica popular e da disposição rimática da mesma origem, que invade inclusive 8 dos seus 9 sonetos, a grande porção seguinte do manuscrito, a que se dá sob a égide da ordenação cronológica, vai perdendo de vista tal referência e se constituindo, em maioria esmagadora, na forma culta do soneto (DAL FARRA, 1994, p. 28).

O ínterim desse movimento é igualmente caracterizado pela existência de quadras em redondilha maior com rimas cruzadas. "Triste Passeio" (ESPANCA, 1994, p. 177), poema de Trocando Olhares e com data de 1 de março de 1916, é um bom exemplo desta construção poética. 1994, p.

É possível perceber que esta estrutura formal é muito semelhante à do poema "A Moda", que também obedece a este mesmo esquema de versos, métrica e rimas. Para além coincidências já apontadas, também há, entre as quadras do manuscrito de Florbela, um poema marcado pela aproximação com o discurso epistolar. "Carta para longe" (ESPANCA, 1994, p. 176) pode ser lido como um convite sedutor enviado pelo eu lírico à pessoa amada que muito tarda em voltar.

1994, p. Assim como ocorre em "Triste passeio", em "Carta para longe", os elementos da natureza personificados também se queixam de saudade. $\mathrm{O}$ sol, a madressilva e a hera se unem à remetente da carta-poema para convencer o destinatário a retornar. Contudo, tanto o endereço do eu lírico como o paradeiro do amado são vagamente expressos. Assim, sem uma localização espacial realmente referenciada, o substantivo "ninho", anaforicamente retomado pelo adjetivo "teu", acaba por denotar, alegoricamente, o lar e/ou o leito, enquanto o dêitico locativo presente no título representa a ausência e o tempo que passa, a espera.

Já, em "A Moda", o destinatário da carta-poema não é o amado ausente, mas as "que pelo Mundo vão/Ansiosas d'encantar". Isso se deve, provavelmente, ao mote (moda), mas é relevante apontar que o desejo de cativar atenção, de prender o olhar, aproximam, de alguma forma, as interlocutoras ao eu lírico de boa parte das quadras de Trocando Olhares. Já o endereço e a assinatura da remetente, "Convento da perfeição" localizado na "Montanha d'Alto Sonhar" e "Soror Saudade", remetem a outros projetos poéticos de Florbela: o Livro de Mágoas e o Livro de "Sóror Saudade".

Na obra de Florbela, a passagem da representação da jovem apaixonada das quadras de feição popular, ara as dramáticas Sóror Saudade, Princesa Desalento e Maria das Quimeras dos sonetos, "tem, como base, a clara interlocução mantida com seus colegas de Faculdade de Direito, "sobretudo com Américo Durão, João Botto de Carvalho e Vasco Camélier, e que vai eclodir definitivamente, em 1923, no Livro de 'Sóror Saudade”' (DAL 
FARRA, 2017, p. 87: "Irmã, Soror-Saudade... Ah, se eu pudesse/ Tocar de aspiração a nossa vida!/ Fazer do mundo a Terra-Prometida/ Que em sonho ainda me aparece" (DURÃO, 1921, p. 90); "Frio e esguio, num de seus pulsos,/ Finos, nervosos, convulsos,/ Terrível, pequenino e inapagável/ O primeiro sinal dum suicídio em vão.../ Firme, inalterável,/ Como a vontade sublime e acesa/ Da Princesa/ Desolação." (CARVALHO, 1919, p. 37); “E as tuas mãos quiméricas e frias/ Adormeceram sobre os crisântemos, / Como um rosário branco de elegias/ Ao debandar dos beijos que nós demos!" (CAMÉLIER, 1997, p. 248)

Claudia Pazos Alonso (1997, p.184) afirma que esses escritores, pares de criação de Florbela, foram, de certo modo, os seus primeiros críticos. Os três revelaram uma atitude de veneração não só pela personalidade singular da mulher, mas, sobretudo, pelo enorme potencial da poetisa.

Florbela, apropriando-se da linguagem de seus colegas e ressignificando a imagem que dela criaram, nomeia-se "uma exilada, uma marginalizada, uma náufraga da vida" (DAL FARRA, 2017, p. 87). Embora tenha garantido a admiração de seus colegas, como Pazos Alonzo aponta, a poetisa não era bem aceita pelo público e pela crítica em geral. Além de pagar o preço que a sociedade de seu tempo impunha àquelas que ousavam romper com os papéis destinados às mulheres, ela ainda escrevia sobre temas vedados à escrita feminina. Seguindo as palavras de Dal Farra (2017), ela sofria, simultaneamente, por não ser reconhecida como Poeta, porque era mulher, e por ser diferente das outras mulheres, porque era Poetisa:

Daí que a sua identidade seja absolutamente móvel, porque permanece pairando entre uma e outra imagem dessas... no limbo!

De maneira que, frequentando os recintos da tradição romântica, ela, como mulher, exerce sobre si uma espécie de punição, porque se aprisiona, se isola incompreendida, fechada num espaço inacessível: o castelo e o convento (DAL FARRA, 2017, p. 87).

O poema "A Moda", como vimos, da mesma forma tem como remetente alguém que está enclausurado distante da realidade limitadora de seu mundo. Esse mesmo ambiente de segregação e reclusão é qualificado como um lugar do sonho e da perfeição, topos muito explorado por Florbela, sobretudo nos sonetos.

Além disto, também encontramos um exemplo do movimento de apropriação e ressignificação muito aproximado daqueles presentes nos sonetos florbelianos, sobretudo no intitulado "Sóror Saudade", resposta ao poema de Américo Durão, "A uma poetisa", no qual emprega o cognome que ele teria, primeiramente, atribuído à Florbela e que se tornaria o mais conhecido dentre todos. 
O eu lírico das quadras encontradas na revista de Chianca parte, justamente, deste mesmo cognome, "Sóror Saudade", que também é apresentado como interlocução, "chamam-me", para se marcar como um ente relacionado a tempos pretéritos, "o passado é meu enlevo", sendo assim, aparentemente, desconcertado e sem credibilidade para tratar do tema, "a Moda, o Presente Palpitante, que varia":

Chamam-me "Soror Saudade",

- Que o passado é meu enlevo...

Mas... sobre modas... quem há-de

Acreditar no que escrevo?!

Não é a Moda, o Presente

Palpitante, que varia?!

A cada instante dif'rente?

Sempre nova em cada dia?!

É o mesmo tipo de movimento entre a identidade atribuída ao sujeito lírico por um homem, seguindo comportamentos sociais predeterminados às mulheres, transfigurando a denominação, que percebemos em poemas florbelianos. Contudo, através de uma argumentação baseada em um exercício conceitual, construído a partir da correlação paradoxal entre passado e presente, acaba por enredar e convencer o leitor que não há alguém melhor para lidar com o assunto. Através de um jogo lógico, o eu lírico comprova que a moda, assim como a memória no caso da saudade, tem a capacidade de transpor o passado para o presente, mitigando as barreiras entre essas duas instâncias temporais, que passam, assim, a se equivaler:

\author{
Pois essa mesma razão \\ Que deste assunto me aparta, \\ Foi buscar-me pela mão \\ Para escrever esta carta!... \\ À força de variar, \\ Moda, linda, a sorrir, \\ Acaba por evocar \\ O Passado ao que há de vir!...
}

Na segunda parte das quadras de "A Moda", percebemos a menção do assunto que mais causava sensações nos anos 1920 em todo o mundo: a eletrizante descoberta do túmulo de faraó Tutancâmon, no Vale dos Reis, em Luxor Ocidental, pelo arqueólogo Howard Carter e por seu patrocinador, Lord Carnarvon. Obviamente que portugueses e brasileiros não escaparam a esse fascínio:

As notícias que quase diariamente os jornais portugueses editavam mostram que havia consciência jornalística deste interesse popular ou "filão noticioso" (que se manifestava numa procura considerável de jornais e revistas, com e sem ilustrações) e que essas edições alimentavam e aguçavam (SALES; MOTA, 2018, p. 229). 
Florbela, muito atenta ao mercado cultural de sua época, com toda certeza teve contato com essa palpitante descoberta. Um trecho de uma carta escrita ao irmão, Apeles, de 25 de março de 1922, indica que a escritora tinha interesse nas pesquisas arqueológicas egípcias em curso no início do século XX:

Apesar de ter estudado um pouco de latim clássico e ter decifrado um não pequeno número de textos em português do século XV, palavra d'honra que me vi tola para decifrar o teu português do século XXV... Eu e o António estudámos com um cuidado meticuloso a tua prosa, tão conscientemente como se fosse uma inscrição misteriosa do túmulo dum faraó... (ESPANCA, 2002, p. 181 - grifos nossos).

Ademais, a alusão concreta aos rituais fúnebres, à mumificação e à profanação da morada eterna do "Faraó Menino", a qual evoca uma atmosfera marcada pelo mistério, pelo sagrado, pelo simbólico, pela transcendência e pela morte, presente no poema, também pode ser considerada como mais um fator de aproximação entre as quadras de "A Moda" e os textos da poetisa, uma vez que muitos de seus poemas abordam esses temas, tanto as quadras de seu passado de iniciante como os sonetos que já a faziam conhecida naqueles idos:

Mas, nas quadras de Florbela, esse topos aparece sobrecarregado de signos de concretude, relativos ao próprio ritual da morte, facto que não se encontra marcado na tradição oral. As ocorrências de "caixão", "cova", "cemitério", "coveiros", do verbo "enterrar" e a precocidade com que a emissão poética se destina à morte são muito expressivas e demonstram que a poetisa imprime a essa convenção um selo pessoal predominantemente carregado (DAL FARRA, 1994, p. 35).

O mote do poema, sugerido pela abertura da tumba do "faraó onipotente", que ordenava, entre outras coisas, a moda em seu país, e que a ordenaria então também em Paris, acaba por valorizar o feminino. Afinal, segundo indica a persona poética: "Eis a Moda erguendo o rogo/ À múmia da deusa Ísis!.... Ou seja, seria a deusa Ísis, aquela associada a funções femininas como a esposa ou a mãe, a verdadeira cultuada com a valorização da cultura egípcia. Com essa inversão, a deusa mumificada, portanto presa em suas ataduras, seria a verdadeiramente cultuada, não o faraó-deus.

Ainda nesta parte do poema são descritos trajes, acessórios e penteados que muito se assemelham ao que, de fato, era prescrito pelas revistas ou seções femininas de vários periódicos da época ${ }^{21}$, como as ilustrações na Figura 2.

Embora se afirmasse "refratária a todas as questões de elegância" (ESPANCA, 2002, p. 207), Florbela também dizia considerar a "porção de arte" que cada vestido e chapéu poderiam conter. Contudo, ao observar a sua correspondência íntima, é possível perceber que a poetisa tinha certas preocupações com a aparência e o vestuário. Em uma passagem de uma 
carta enviada à Júlia Alves, a poetisa comenta que a demora no envio de um retrato seu fora causada pela necessidade de esperar que um traje mais "fixe", encomendado a uma modista, ficasse pronto. Tudo isso porque Florbela não gostaria de dar à amiga lisboeta a impressão de ser uma camponesa perdida nas charnecas do Alentejo. Já, em missiva destinada ao irmão, que estava no Brasil, Florbela comenta, com certo humor, as dificuldades para pagar a conta feita com um alfaiate que era tão "pelintra" quanto ela:

Mano Peles,

Lá vai a última e irrevogável cravadela: envio-te a conta da toilette que me ofereceste. Fui a um alfaiate pelintra para conseguir um preço razoável, e foi o que felizmente aconteceu. Como eu não podia dispor deste dinheiro, pedi emprestado ao meu cunhado Manuel, que é bom rapaz e que imediatamente a isso se prontificou; peço-te pois para, por toda esta semana, fazeres o favor de lhe entregar essa importância que ele me emprestou para o pagamento do vestido. [...] E mais uma vez obrigada; desejo que não seja a última vez que navegues até ao Brasil para não ser a última toilette oferecida à mana pelintra. $[\ldots]$

O vestido está fixe, digno da mana dum mano fixíssimo.

Beijos ao Peles urso e os mercis todos da Bela

P.S. - Se o mano Peles estiver tão pelintra como a mana pelintra, não pague nada, que eu quando puder saldarei a minha dívida e, mesmo assim, tudo está fixe.

Beijos e abraços da

Bela

(ESPANCA, 2012, p. 239)

A correspondência ainda indica que Florbela Espanca era uma mulher atenta à moda, mesmo que lidasse com ela de maneira irônica. É o que revela a carta ao amigo Américo Durão, redigida em Vila Viçosa, em 5 de janeiro de 1920, na qual ela comenta ser a própria Soror Saudade e conta como leu o livro do poeta:

Segundo rezam as crónicas, eu já sou um pouco doida, imagine como ficarei depois disto!... Só hoje me levantei um pouco. Logo pela manhã muito vaidosamente pedi um espelho para me ver. Fiquei contente: muito pálida, com a boca muito pálida, com umas grandes olheiras roxas, a cabeça envolvida com ligaduras brancas, eu era mesmo... mesmo... adivinhe quem? Pois era mesmo... mesmo... Soror Saudade!

$[\ldots]$

V. não tem notado uma coisa interessante? Eu estou sempre vestida de verde ou de roxo nos dias em que o encontro.

Pois nessa noite, ainda lembro-me muito bem - eu tinha um vestido verde todo coberto de rendas prateadas. $\mathrm{O}$ meu vestido não era, certamente, um Redfern ou o último modelo de Worth... (ESPANCA, 2002, pp. 232-233). 
De volta ao poema encontrado na revista Portugal, em relação à sua última parte, é possível que ela consista em um retorno à comprovação de que a Moda, assim como a Saudade, seria capaz de vencer os limites da "Morte":

\author{
Num coval ou num museu \\ O velho Egito dormita \\ Tal e qual como morreu! \\ A Moda não!... Ressuscita! \\ Transformada, redimida; \\ Mais sutil e espiritual! \\ Perpétua dona da Vida! \\ Como divina, imortal! \\ Bendita a Moda! Saudade \\ Que a Morte envolve d'enganos! \\ Pois a velha Humanidade \\ Remoçou de três mil anos!...
}

O ressurgimento ou o renascimento também é um topos comum ao poema "A Moda" e à obra de Florbela, assim como o eu lírico das quadras encontradas na revista de Chianca se apropria do ritual fúnebre egípicio, que pressupunha a ressureição, para salientar a capacidade de renovação da moda. Segundo essa perspectiva, há motivo para o uso de quadras no poema "A Moda" em vez da composição em soneto. Como o poema se propõe a mostrar como algo do passado ressurge no presente, nada mais natural, unindo forma ao conteúdo, do que recuperar um modelo formal da tradição para tratar de tema da atualidade.

Além disso, como lembra Maria Lúcia Dal Farra, “já na primeira Florbela, a morte ganha uma avaliação positiva, de universo liberto das cadeias da convenção, das hierarquias, das referências codificadas, da proibição, das restrições" (1996, p. XXIX). Assim, em poemas florbelianos, como "Charneca em Flor” (ESPANCA, 1996, p. 209), o erotismo é uma força vital, renovadora, capaz de fazer com que a monja se liberte de sua mortalha e renasça como mulher. 1996, p. Em todo poema "A Moda" é possível perceber o uso das maiúsculas alegorizantes, bem ao gosto dos simbolistas, que intensificam, personificam e mitificam elementos, como a "Moda", o "Passado", o "Presente", a "Vida" e a "Morte". O mesmo ocorre com Florbela, segundo Dal Farra, sobretudo a partir do ciclo de sonetos dedicados a Durão.

“Quem há de acreditar?" - pergunta a voz do poema que aqui apresentamos. Seria o poema "A Moda", publicado por Soror Saudade na revista Portugal, do Rio de Janeiro, em 1923, uma criação de Florbela Espanca resgatada das tumbas pela pesquisa em periódicos no acervo do Real Gabinete Português de Leitura? Aceitando-se a resposta afirmativa, alteram-se alguns dados da historiografia literária dessa escritora. Florbela teria, então, em vida, publicado também no Brasil, poema em quadras, sob pseudônimo. Mostramos que foi possível o contato entre o escritor Rui Chianca e o 
tenente Apeles Espanca durante as comemorações pela travessia aérea do Atlântico Sul em 1922, o período de finalização do Livro de "Sóror Saudade". Percebemos que Florbela Espanca era uma desconhecida no Brasil nessa época, mesmo junto à colônia imigrante portuguesa, o que permitiria que esse poema tivesse ficado ignorado nas páginas da revista carioca. Sobretudo, identificamos no poema "A Moda" relações formais com produções florbelianas, mesmo quanto ao uso das quadras, e diversas ligações quanto ao tratamento do feminino e das interlocuções que ela costuma estabelecer com as identidades que lhe eram atribuídas, como "Sóror Saudade".

\section{PERIÓDICOS CONSULTADOS:}

A Noite n. 4153, de 22 de junho de 1923

A Noite n. 5768, de 12 de dezembro de 1927

A Rua n. 144, de 26 de junho de 1922

Correio da Manhã n. 8489, de 2 de junho de 1922

Correio da Manhã n. 8556, de 8 de agosto de 1922

Correio da Manhã n. 8579, de 31 de agosto de 1922

Correio da Manhã n. 8588, de 9 de setembro de 1922

Diario Official n. 14204, de 25 de julho de 1922

Illustração Pelotense a. 9 n. 11-12, de 15 de junho de 1927

Illustração Pelotense a. 9 n. 4, de 15 de fevereiro de 1927

Lusitânia: revista ilustrada de atualidade e de aproximação luso-brasileira, n. ${ }^{\circ}$ 78, de 16 de abril de 1932

Lusitânia: revista ilustrada de atualidade e de aproximação luso-brasileira, n. ${ }^{\circ}$ 54, de 16 de abril de 1931

O Paiz n. 13760, de 23 de junho de 1922

O Paiz n. 13797, de 30 de julho de 1922

O Paiz n. 138483, de 14 de setembro de 1922

O Paiz n. 14080, de 9 de maio de 1923

Pátria Portuguesa n. ${ }^{\circ}$ 299, de 30 de agosto de 1930

Pelo Mundo n. 11, de dezembro de 1927

Pelo Mundo n. 11, dezembro de 1923

Portugal n. 1, 14 de agosto de 1923 
Portugal n. 2, de 31 de agosto de 1923

Portugal n. 11, de 15 de janeiro de 1924

Revista da Semana n. 19, de 5 de maio de 1923

\section{REFERENCIAS BIBLIOGRÁFICAS}

ALONSO, Cláudia Pazos. Images of the self: a study of Florbela Espanca. University of Oxford. D. Phil. in Medieval and Modern Languages (Portuguese). 1994.

. Imagens do eu na poesia de Florbela Espanca. Lisboa: Imprensa Nacional — Casa da Moeda, 1997.

CAMELIER, Vasco. Livro de Horas das Princesas Doentes. Lisbon: [s.ed.], 1919.

CARVALHO, João Botto de. Sol Poente. Lisboa: Imprensa Libanio da silva, 1919.

CARVALHO, Maria de. Figuras Imortais. Lusitânia: revista ilustrada de atualidade e de aproximação luso-brasileira, n. ${ }^{\circ}$ 78, de 16 de abril de 1932.

DAL FARRA, Maria Lúcia. O Errante Feminino em Florbela Espanca. ContraCorrente: Revista do Programa de Pós-Graduação Interdisciplinar em Ciências Humanas, [S.1.], n. 3, maio 2017. ISSN 2525-4529. Disponível em: $<$ http://periodicos.uea.edu.br/index.php/contracorrente/article/view/493>. Acesso em: 29/09/2019.

. "Florbela: um caso feminino e poético". In: ESPANCA, Florbela. Poemas de Florbela Espanca. Estudo introdutório, organização e notas de Maria Lúcia Dal Farra. São Paulo: Martins Fontes, 1996.

DURÃO, Américo. Poesias Completas. Lisboa: Imprensa Nacional/ Casa da Moeda, 1999.

ESPANCA, Florbela. Trocando olhares. Estudo introdutório, estabelecimento de texto e notas de Maria Lúcia Dal Farra. Lisboa: Imprensa Nacional Casa da Moeda 1994.

. Poemas de Florbela Espanca. Estudo introdutório, organização e notas de Maria Lúcia Dal Farra. São Paulo: Martins Fontes, 1996.

. Florbela Espanca - poesias - obras completas - volume 1. Organização, apresentação e notas de Michelle Vasconcelos Oliveira do Nascimento. São Paulo: LiberArts, 2016.

Afinado Desconcerto. Estudo introdutório, estabelecimento de texto e notas de Maria Lúcia Dal Farra. São Paulo: Iluminuras, 2002. 
MAGGIOLLY, Judith. Crónica da Quinzena. Lusitânia: revista ilustrada de atualidade e de aproximação luso-brasileira, n. ${ }^{\circ}$ 54, de 16 de abril de 1931.

SALES, José Das Candeia; MOTA, Susana. Tutankhamon em Portugal (1923-1926): Da superstição ao ensaio académico ou os percursos que vão da maldição da múmia ao Hino a Aton. História. Porto: FLUP. IV Série. Vol. $8 n^{\circ} 2,2018$.

\section{Recebido para avaliação em 30/09/19 Aprovado para publicação em 06/01/20}

\section{NOTAS}

1 Professora de Literatura Portuguesa do Instituto de Letras da UERJ. Doutora em Literatura Comparada pela mesma universidade. Pesquisadora do Polo de Pesquisas Luso-Brasileiras do Real Gabinete Português de Leitura. Investigadora colaboradora do Centro de Estudos Clássicos da Faculdade de Letras da Universidade de Lisboa.

2 Professor de Literatura Portuguesa do Instituto de Letras da UERJ. Doutor em Literatura Comparada pela UFF. Pesquisador do Polo de Pesquisas Luso-Brasileiras do Real Gabinete Português de Leitura. Investigador colaborador do Centro de Estudos Clássicos da Faculdade de Letras da Universidade de Lisboa. Tem pesquisado a relação entre literatura e imprensa periódica no contexto luso-brasileiro e publicou recentemente livro com estudo, antologia e bibliografia sobre a escritora Maria José Canuto (1812-1890) pela Biblioteca Nacional de Portugal e pelo CLEPUL junto ao projeto "Senhoras do Almanaque".

3 Projeto intitulado "Escritoras portuguesas na imprensa periódica do Brasil: laços transatlânticos de ação (1890-1930)", que foi contemplado pelo edital universal do CNPq, processo: 405146/2018-3, coordenado por Eduardo da Cruz, com participação das doutoras Ana Cristina Comandulli da Cunha, Andreia Alves Monteiro de Castro, Elisabeth Martini, Vanda Anastácio e Isabel Lousada.

4 A partir dos catálogos do Real Gabinete Português de Leitura e da Fundação Biblioteca Nacional chegamos aos seguintes títulos: União Portuguesa (RJ, 1899-1908); Portugal Moderno (RJ, 1899-1918?); Pátria Portuguesa (SP); Pátria Portuguesa (RJ, 1925-1934); Diário Português (RJ, 1932-1936); Lusitânia (RJ, 1929-1934); Revista Portuguesa (SP); Portugal: revista portuguesa (RJ, 1923-1928); O Lusitano: órgão da colônia portuguesa no Rio Grande do Sul (RS, 1912); Portugal na Guerra (RJ, 1916); A Bandeira Portuguesa (SP, 1907-1918); A Pátria: órgão da colônia portuguesa (SP, 1901-1902); A Sátira Portuguesa (RJ, 1901); O Lusitano: órgão dedicado à colônia portuguesa (SP, 1908); O Lusitano: órgão da colônia portuguesa no Brasil (RJ, 1906-1908); Opinião Portuguesa (RS, 1905); A Alvorada: semanário republicano: órgão do Partido Republicano Português (RS, 1913); A Época Portuguesa (RJ, 1918); El-Rei de Portugal (RJ, 1911); Jornal Português: defensor dos interesses portugueses no Brasil (RJ, 1918-1934); O Estudo: órgão dos alunos do Liceu Literário Português (RJ, 1918-1919); O Lusitano: órgão dos interesses portugueses no Estado do Paraná (PR, 1916); O Realista: órgão da Liga Monárquica (RJ, 1912-1913); Restauração: órgão monárquico português no Brasil (RJ, 1911); Nova Lusitânia: semanário de propaganda de Portugal (RJ, 1921); Portugal (RJ, 1926); Portugal Ilustrado: revista mensal de propaganda portuguesa e intercâmbio luso-brasileiro (RJ, 1928); Semana Portuguesa: revista ilustrada de propaganda de Portugal (RJ, 1924-1975); União Portuguesa (RJ, 1929); Alma Lusitana: revista semanal, literária, política e noticiosa (RJ, 1919); Eco Lusitano (PA, 1908-1910); O Heraldo (PA, 1913).

$5 \mathrm{Na}$ transcrição que Cláudia Pazos Alonso faz das respostas dadas à Florbela Espanca, então Florbela Moutinho, na seção "A Correspondência das Nossas Leitoras”, há o seguinte conselho: "Se quer vir a prezar o seu nome literário e se tem consciência da originalidade das suas produções poéticas não deve tomar agora um pseudónimo” (apud ALONSO, 1994 , p. 248).

6 A busca foi feita com as expressões "Florbela Espanca", "Florbella Espanca", "Florbela Moutinho" e "Florbella Moutinho". 
7 Cf. Pelo Mundo n. 11, de dezembro de 1927, p. 116.

8 Cf. Illustração Pelotense a. 9 n. 11-12, de 15 de junho de 1927, p. 4.

9 Cf. Illustração Pelotense a. 9 n. 4, de 15 de fevereiro de 1927, p. 20.

10 Cf. A Noite n. 5768, de 12 de dezembro de 1927, p. 5.

11 Mantivemos a ortografia original do nome do faraó para não alterar a sonoridade do verso.

12 Poemas de Florbela Espanca. Estudo introdutório, organização e notas de Maria Lúcia Dal Farra. São Paulo: Martins Fontes, 1996.

13 Florbela Espanca - poesias - obras completas - volume 1. Organização, apresentação e notas de Michelle Vasconcelos Oliveira do Nascimento. São Paulo: LiberArts, 2016.

14 “Conforme temos noticiado, realiza-se domingo proximo, no Lyrico, o festival em homenagem ao talentoso escriptor Ruy Chianca, promovido por um grupo de figuras de relevo na colonia lusitana, por motivo da fundação da revista Portugal." ("Em homenagem a Ruy Chianca”. O Paiz n. 14080, 9 de maio de 1923, p. 2, c. 6).

15 Referimo-nos ao volume Sempre Tua: correspondência amorosa 1920-1925, organizado por Dal Farra, publicado em 2012.

16 Cf. Diario Official n. 14204, de 25 de julho de 1922.

17 Cf. Correio da Manhã n. 8556, de 08/08/1922, p. 3.

18 Cf. Correio da Manhã n. 8579, de 31/08/1922, p.1.

19 Cf. Correio da Manhã n. 8588, de 09/09/1922, p.3.

$20 \mathrm{Na}$ introdução do livro Florbela Espanca - Trocando Olhares, Maria Lúcia Dal Farra aponta Madame Carvalho, Júlia Alves, Raul Proença, Américo Durão e a literatura oral como principais interlocutores da jovem Florbela e da sua poética.

21 Ver também as figuras presentes em: Revista da Semana n. 19, de 5 de maio de 1923, p. 31 e Pelo Mundo n. 11, dezembro de 1923, p. 41 